\title{
The Effect of Life Satisfaction and Religiosity on Happiness among Post Graduates in Malaysia
}

\author{
Mohd Amirul Rafiq Abu Rahim ${ }^{1}$ \\ (Institute for Mathematical Research, Faculty of Science, University Putra Malaysia, Malaysia)
}

\begin{abstract}
The main objective of this research is to examine the effect of life satisfaction and religiosity on happiness among postgraduates in Malaysia. A total of 124 questionnaires were applied to selected postgraduates in three public universities. A multiple logistic regression analysis was performed to examine the effect of life satisfaction and religiosity on happiness among respondents. As a result from the data collected, it was found that, all factors (life satisfaction and religiosity) were significantly give an effect to individual's happiness. Among predictors, the variable of Life Satisfaction gives the strongest effect to individual's happiness as compared to religiosity and frequent of prayer. This research can be beneficial to the field of happiness study especially in Malaysia context which comprise of multi racial citizens.
\end{abstract}

Keywords - Happiness, religiosity, life satisfaction, logistic regression.

\section{INTRODUCTION}

Measuring happiness is a subjective matter depending on the issues that are deemed important to the individual, the community and the nation. In today's world, modern theories in happiness study have given more focused on economic prosperity and on the other hand, people's happiness is measured by wealthy and economic conditions in their country. But nowadays, the happiness topic reflects the larger societal trends concerning the values of individual, the importance of subjective views in evaluating life, and the recognition that one's well-being does not necessarily include positive elements that transcend economic prosperity. Happiness seems to be the one held by the majority of people and be considered to be more important than the pursuit of money. The World Happiness Report shows that the happiness was belong to the developed nations like Finland, Denmark, Norway and Netherlands which already known that those nations having better life structure as well as having perfect environment. Least developed and poor nation especially African country and certain country in Asia were categorized as unhappiness country. Growth in the happiness studies reflects the larger societal trends concerning the values of the individual and the importance of subjective views in evaluating life. The meaning of happiness including life satisfaction, well-being, global life-worth, life quality, hedonistic level, euphoria, elation, enjoyment, optimism and success in achieving goals. All these words reflect the meaning of happiness of an individual (Veenhoven, 1988). It should be noted that happiness should not only be measured by one special area of life such as working environment, private life, wealth and physical life. Happiness shows how much an individual is satisfied with their life in overall without omitting the values of religiosity. The present study explores the effect of life satisfaction and religious attendance on happiness among post graduates in Malaysia. The study is beneficial in explaining happiness concept in the context of Malaysian society since it was found that only a few studies on happiness has been done in Asia. Thus, the present study can contribute to cross culture knowledge in measuring happiness among Eastern perspective.

\section{REVIEW OF THE LITERATURE}

Several papers have discussed about the interrelationship between life satisfaction, religious attendance and happiness. Material factor should not be seen as a crucial factor in determining individual happiness. Individual life satisfaction and religious attendance should be taken into consideration as greater aspects in measuring happiness. Some papers found that happiness is not associated with people material accumulation, but with their perceived inner world (Kau, Phua, \& Swinyard, 2001), religious attendance (Abdel-Khalek, 2006; Childs, 2010; Sahraian, Gholami, Javadpour, \& Omidvar, 2011) and life satisfaction (San Martín, Perles, \& Canto, 2010).

Kau, Phua \& Swinyard (2001) tried to examine the relationships between happiness, materialism and religious attendance in two nations United States and Singapore. They found that happiness is negatively related to materialism to both country studied and people in United States are less materialistic but happier as compared to Singapore. They conclude that people perceived inner world would give significant effect to their happiness than material accumulation. For instance, the author suggests that happier people do not consider wealthy as the factor on measuring their happiness while happy people might have their own material wealth for their 
happiness elsewhere. These results however illustrate that material aspects do not necessary useful in predicting an individual happiness.

A study conducted by Abdel-Khalek (2006) on the significant relations on happiness, health and religiosity among Kuwaiti Muslim undergraduate students found that the main predictor of happiness was mental health while religiosity contribute small variance in predicting happiness. Based on his findings however, the data provide strong evidence that religious respondents are happier as compared to non religious respondents. Another literature suggests that a religious attendance give significant effect among students was conducted by Sahrain et. al (2011). The greater the individual relationship with God, the happier they are in their life. Childs (2010) has found that of individual perceived relationship with God and individual perceived relationship with other congregants give mediating effect on happiness. A study by San Martin et. al (2010) had found the association between happiness and life satisfaction and they suggest both happiness and satisfaction should be measured distinctively. The researcher evaluates the three orientations of happiness (namely pleasure, meaning and engagement) and their relation to happiness in 320 university students as a sample. They finally found that pleasure was most closely related to happiness while engagement related to life satisfaction.

Lucas et. al (1996) suggest that the tangible and intangible aspects of life, weighs the good against the bad and arrives could indicate that individual's life satisfaction. Different scholar use different measures of happiness which related to religious attendance and life satisfaction. This present study attempt to examine the effect of religiosity and overall life satisfaction among postgraduates in three selected public universities in Malaysia.

\section{METHODOLOGY}

A questionnaire was designed to elicit information from postgraduates' in three sampled university. The sampling frame for the study consisted of all public universities in Klang Valley area in Malaysia. All questionnaires were self-administered. For the study, usable data from 124 students were analyzed. The respondents were asked to answer a set of questionnaires which consists of respondents personal information and several questions adopted from Lyubomirsky \& Lepper's (1999), Satisfaction with Life (Diener et. al,1985) and several questions on religiosity.

For the purpose of this article, the researcher only interested to measure the effects of religiosity on respondents happiness. From the questionnaire, only four self-rating scales were selected to assess happiness, and religiosity. The self-rating scales were as follows:

1. Do you feel happy in general? (0: No; 1: Yes)

2. I am totally satisfied with my life? (0: No; 1 :Yes)

3. How often do you pray? (0: Never; 9 : Very often)

4. What is your level of religiosity? (0: Extremely non-religious; 8: Very religious)

The subject was requested to answer the questions based on the alternatives in each one of the four ratings, separately. They were advised to respond according to their global estimation and general feelings, and not as a present state.

The responses were then analyzed using logistic regression method where to determine the impact of independent variables simultaneously. The dependent or the outcome variable of interest for the study were "Do you feel happy in general?" was constructed as a 'yes/no' dichotomous indicator. The categorical dependent variable of the study necessitated the use of multiple logistic regression models for investigating whether the likelihood of individual happiness was related to the selected predictors as mentioned above. The specific logistic regression model fitted to the data was:

$$
\text { Logit }(\text { Happiness })=b_{0}+b_{1}(\text { Life Satisfaction })+b_{2}(\operatorname{Pr} a y)+b_{3}(\text { Re ligiosity })
$$

Where $b_{1}, b_{2}$ and $b_{3}$ are the logistic coefficients of estimates for the parameters $\beta_{1}, \beta_{2}$ and $\beta_{3}$.

\section{RESULTS}

A sample of 124 (50 male and 74 female) volunteer of Malaysian postgraduates in three selected universities in Klang Valley area was recruited. The age distribution of the respondents ranged from 21 to 48 years old. About $60 \%$ of respondents currently pursuing their Masters Degree and $40 \%$ Doctorate study. Among the respondents, approximately $78 \%$ were Malays and Bumiputeras, $14 \%$ Chinese and $8 \%$ Indian. About $77 \%$ of respondents were Muslims, 13\% Christians, 6.5\% Buddhists and 4\% Hindus. Generally, the sample distribution almost represents Malaysian different races and religion. According to respondents marital status, about $70 \%$ of respondents is single, $28 \%$ were married and about $2 \%$ is divorced. About $33 \%$ of respondents claimed that they are not felt happy generally on their life and $67 \%$ said that they are happy in general. According to education category, the results showed that about $53 \%$ of Master Degree students were happy in general as compared to $47 \%$ of Doctorate students. Based on gender, the results showed that the female students (61\%) was happy as compared male students (39\%). Table 1 shows the sample distribution for the study. 
In logistic regression, the independent variables need not to be interval, nor normally distributed, nor linearly related nor of equal variance within each group. The most important assumption in logistic regression is that the dependent variable must be in two categories (dichotomous). Logistic regression analysis requires that the independent variables be metric or dichotomous. The binary logistic regression procedure was then performed by using R software to determine whether the likelihood of individual happiness could be predicted by the independent variables. Data from 124 postgraduates in three sampled university in Klang Valley area were included in this analysis.

The results of the logistic regression analysis showed that the full model which considered all the three independent variables together was statistically significant, $\chi 2=12.085, \mathrm{df}=5, \mathrm{~N}=124, \mathrm{p}<.034$, indicating that the predictors as a set reliably distinguished between happy and unhappy people on their life in general. This implies that the odds for postgraduates to indicate that they felt happy in general were related to the three independent variables under study (Life Satisfaction, How often they pray and Level of religiosity). Table 2 presents a summary of the raw score binary logistic regression coefficients, Wald statistics, p-value, odds ratio along with a 95\% Confidence Interval of Wald. Wald statistics indicate that all the independent variables significantly predict the individual happiness (of being happy or unhappy). The prediction equation for the analysis was:

\section{Logit $($ Happiness $=1)=-6.017+1.162($ Life Satisfaction $)+0.373(\operatorname{Pr}$ ay $)+0.622($ Re ligiosity $)$}

The strongest predictor of individual happiness among postgraduates was Life Satisfaction. The odds ratio for Life Satisfaction was 3.197 i.e., the odds of postgraduates indicating that they are happy in general increase by a factor of 3.197 if they are satisfied with life as compared to not satisfied with life. Other predictors that made a significant effect to the model (Happiness) were Pray and Religiosity. The more frequent they pray, the more likely they would report that they are happy. Thus, the odds of individual happiness among postgraduates increase by a factor 1.452 for a unit increase in frequency of pray. In other words, the odds of individual happiness among postgraduates increase by $45 \%$ for a unit increase in frequency of pray. The level of religiosity among postgraduates and their happiness were strongly related. The higher the level of religiosity, the more likely they would report that they are happy. Thus, the odds of individual happiness among postgraduates increase by a factor 1.862 for a unit increase in the level of religiosity. In other words, the odds of individual happiness among postgraduates increase by $86 \%$ for a unit increase in level of religiosity.

Table 1: Respondent's demographic profiles

\begin{tabular}{|c|c|c|c|}
\hline \multicolumn{2}{|c|}{ Respondents Profile } & Frequency & Valid Percent \\
\hline \multirow{5}{*}{ University } & A & 50 & 40.3 \\
\hline & $\mathrm{B}$ & 36 & 29.0 \\
\hline & & & \\
\hline & $\mathrm{C}$ & 38 & 30.6 \\
\hline & Total & 124 & 100.0 \\
\hline \multirow{3}{*}{ Gender } & Male & 50 & 40.3 \\
\hline & Female & 74 & 59.7 \\
\hline & Total & 124 & 100.0 \\
\hline \multirow{6}{*}{ Age Status } & 21 to 25 years old & 52 & 42.3 \\
\hline & 26 to 30 years old & 38 & 30.9 \\
\hline & 31 to 35 years old & 8 & 6.5 \\
\hline & 35 to 40 years old & 16 & 13.0 \\
\hline & 41 years old and above & 9 & 7.3 \\
\hline & Total & 123 & 100.0 \\
\hline \multirow{4}{*}{ Marital Status } & Single & 87 & 70.2 \\
\hline & Divorced & 2 & 1.6 \\
\hline & Married & 35 & 28.2 \\
\hline & Total & 124 & 100.0 \\
\hline Race & Malay & 92 & 74.2 \\
\hline
\end{tabular}




\begin{tabular}{llcc} 
& Chinese & 18 & 14.5 \\
& Indian & 9 & 7.3 \\
& $\begin{array}{l}\text { Bumiputra Sabah / } \\
\text { Sarawak }\end{array}$ & 5 & 4.0 \\
\cline { 2 - 4 } & Total & $\mathbf{1 2 4}$ & $\mathbf{1 0 0 . 0}$ \\
\hline \multirow{5}{*}{ Religion } & Muslim & 95 & 76.6 \\
& Hindus & 5 & 4.0 \\
& Buddhists & 8 & 6.5 \\
& Christians & 16 & 12.9 \\
\cline { 2 - 4 } Education Level & Total & $\mathbf{1 2 4}$ & $\mathbf{1 0 0 . 0}$ \\
\cline { 2 - 4 } & Master Degree & 74 & 59.7 \\
\cline { 2 - 4 } & Doctorate (Phd) & 50 & 40.3 \\
\hline
\end{tabular}

Table 2: Logistic regression predicting the likelihood of individual happiness

\begin{tabular}{ccccccc}
\hline Predictor & B & S.E. & Wald & df & Sig. & Odds Ratio \\
\hline Pray & 0.373 & 0.167 & 5.011 & 1 & 0.025 & 1.452 \\
Religiosity & 0.622 & 0.302 & 4.23 & 1 & 0.04 & 1.862 \\
Life Satisfaction & 1.162 & 0.431 & 7.287 & 1 & 0.007 & 3.197 \\
Constant & -6.017 & 1.99 & 9.138 & 1 & 0.003 & 0.002 \\
\hline
\end{tabular}

\section{CONCLUSION}

The main objective for the study was to investigate the effect of life satisfaction and religiosity on happiness among postgraduates in Malaysia. The dependent variable for the study was 'do you feel happy in general' which measured by 'Yes' or 'No' (dichotomous scale). There are three independent variables for the study that was used to predict the dependent variable that is 'I am totally satisfied with my life', 'how often do you pray' and 'what is your level of religiosity?'. From the analysis, we found that all of the independent variables were statistically significance in predicting the dependent variable. In other words, we can say that the selected independent variables are important correlates of individual general happiness among postgraduates in Malaysia. Life satisfaction was the strongest predictors of individual general happiness. Life satisfaction measures how individual evaluate their life as a whole rather than the current feelings. This result lead us to captures a reflective assessment of which life circumstances and conditions are really important to predict individual happiness. Self-rating of level of religiosity in the study shows that religiosity would probably an important element for respondents in determining their happiness in life. The frequent of pray also give significant relations to respondents happiness. This result shows that, their strong relationship to God would most important factor in determining individual's happiness. The limitations for the study was limited ranges of respondents due to the scope of study was postgraduates students. It is possible to get broad distributions of respondent's ages by increasing the sample sizes for respondents. Future research in examining the relationship between religiosity, life satisfaction and happiness should require larger data since the results will potentially reflects in larger populations in community.

\section{ACKNOWLEDGEMENT}

I would like to thank the post graduate students who willingly gave their time to participate in the study. Special thanks to Dr. Mohd Bakri Adam and Associate Professor Dr. Mat Rofa Ismail for their ongoing support throughout the study. My gratitude to all the lecturers who were involved directly or indirectly in this research and especially to my friend, Miss Siti Aishah Mohd Shafie who willingly shared ideas and discussions on data processing as well as in writing this article. The views expressed in this article are those of the author and do not necessarily reflect the policies of any organization. 


\section{REFERENCES}

[1]. Abdel-Khalek, A. M. (2006). Happiness, health, and religiosity: Significant relations. Mental Health, Religion \& Culture, 9(1), 8597.

[2]. Abolfathi Momtaz, Y., Hamid, T.-A., Ibrahim, R., Yahaya, N., \& Tyng Chai, S. (2011). Moderating effect of religiosity on the relationship between social isolation and psychological well-being. Mental Health, Religion \& Culture, 14(2), 141-156.

[3]. Agresti, A. (2007). An Introduction to Categorical Data Analysis, second edition. New York: Wiley.

[4]. Ambrey, C. L., \& Fleming, C. M. (2011). The influence of the natural environment and climate on life satisfaction in Australia, (February), 1-39.

[5]. Brülde, B. (2006). Happiness and the Good Life. Introduction and Conceptual Framework. Journal of Happiness Studies, 8(1), 1-14. doi:10.1007/s10902-006-9002-9

[6]. Childs, E. (2010). Religious Attendance and Happiness : Examining Gaps in the Current Literature - A Research Note. Department of Sociology, University of Notre Dame, 49(3), 550-560.

[7]. Diener, E., Emmons, R., \& Griffin, S. (1985). The Satisfaction with Life Scale. Journal of Personality Assessment, 49, 71-75.

[8]. Kau, A., Phua, H., \& Swinyard, W. R. (2001). Happiness, materialism, and religious experience in the us and singapore. Journal of Happiness Studies, 2(January 2000), 13-32.

[9]. Lucas, R. E., Diener, E., \& Suh, E. (1996). Discriminant validity of well-being measures. Journal of Personality and Social Psychology, 71, 616-628.

[10]. Lyubomisky, S., \& Lepper, H. (1999). A Measure of Subjective Happiness: Preliminary realibility and Construct Validation. Social Indicators Reseacrh, 46, 137-155.

[11]. Sahraian, A., Gholami, A., Javadpour, A., \& Omidvar, B. (2011). Association Between Religiosity and Happiness Among a Group of Muslim Undergraduate Students. Journal of religion and health, 10-13. doi:10.1007/s10943-011-9484-6

[12]. San Martín, J., Perles, F., \& Canto, J. M. (2010). Life satisfaction and perception of happiness among university students. The Spanish journal of psychology, 13(2), 617-28. Retrieved from http://www.ncbi.nlm.nih.gov/pubmed/20977012

[13]. Veenhoven, R. (1988). The utility of happiness. Social Indicators Research, 20(4), 333-354. doi:10.1007/BF00302332

[14]. Veenhoven, R. (1991). Is happiness relative? Social Indicators Research, 24(1), 1-34. doi:10.1007/BF00292648

[15]. Veenhoven, R. (2003). Hedonism and Happiness. Journal of Happiness Studies, 4(4), $437-457$. doi:10.1023/B:JOHS.0000005719.56211.fd

[16]. Veenhoven, R., \& Hagerty, M. (2006). Rising Happiness in Nations 1946-2004: A Reply to Easterlin. Social Indicators Research, 79(3), 421-436. doi:10.1007/s11205-005-5074-x 